\title{
Commentary: Perioperative transfusion--Awakening the immunologic beast, or alerting us to unrecognized frailty?
}

\author{
R. Taylor Ripley, MD, and Shawn S. Groth, MD
}

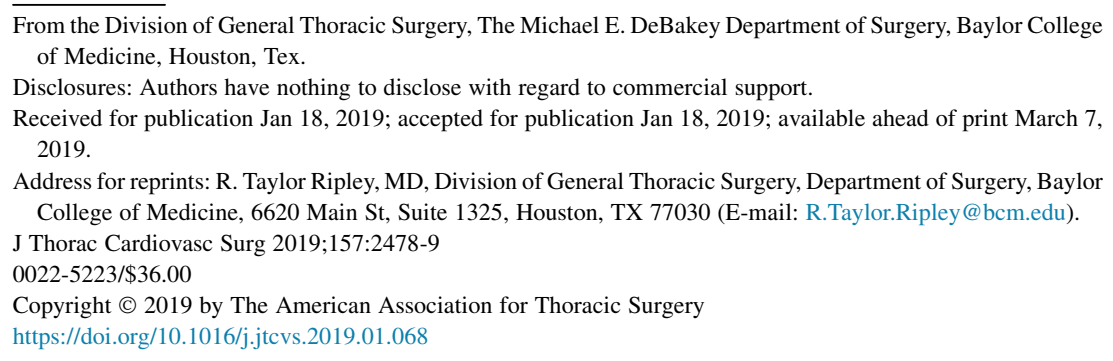

In the introduction of the their article in this issue of the Journal, Latif and colleagues" ${ }^{1}$ state, "Perioperative blood transfusions have been associated with recurrence and decreased survival following surgical resection of nonsmall cell lung cancer...The underlying reasons for this association are unclear, but the immunosuppressive effects of allogeneic blood transfusions have been suggested as one plausible mechanism." The innate and cellular immune systems are important antineoplastic mechanisms, and compromising their function may lead to worse oncologic outcomes. Should we blame the immune system for the higher recurrence rates and lower survival rates associated with blood transfusions?

Latif and colleagues ${ }^{1}$ found that receiving more than 1 unit of blood after pulmonary resection for non-small cell lung cancer carried a dose-dependent increased risk of recurrence and lower survival. Latif and colleagues ${ }^{1}$ concede that patients receiving transfusions tended to have more medical comorbidities, a higher stage of disease, and more postoperative complications. Although they adjusted for age, comorbidities, and stage in their multivariable analyses, they did not adjust for complications. Yet complications are an independent predictor of worse long-term cancer-specific survival rates after lobectomy. ${ }^{2}$ Complications may be (in part) confounding the association between transfusion and higher recurrence and lower survival rates. They did adjust for operative approach, however, which is important because thoracoscopy is associated with less impairment of cellular cytotoxicity and improved survival at 4 years relative to thoracotomy. ${ }^{3,4}$

The lack of difference in outcomes with 1 unit of blood transfused is a particularly interesting finding of this study. The reason, however, is unclear. If the immunosuppressive effect of blood transfusion is important, is the immunologic impact of a single transfusion inconsequential, with a threshold (eg, 2 or more units) needed to frailty.

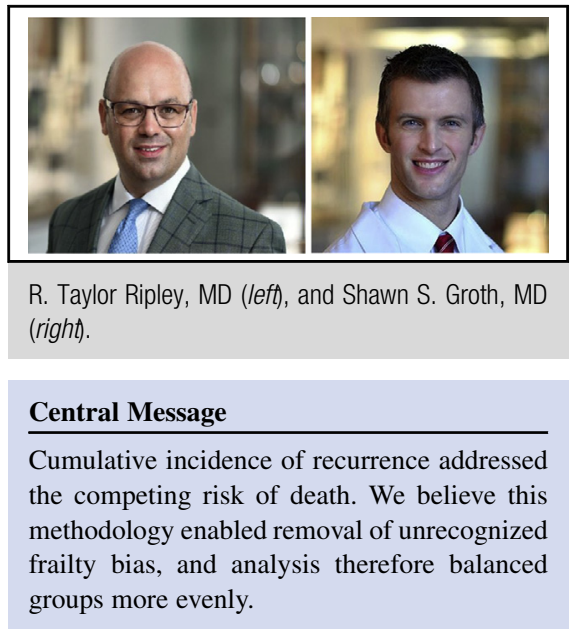

See Article page 2469.

cause clinically relevant immunosuppression? Because the threshold for transfusion was left at the discretion of the treating physicians, an important source of bias in this study, perhaps patients who received 1 unit had less of a physiologic demand for transfusion and therefore this transfusion had a lesser immunologic impact after accounting for confounders.

The statistical methods are a strength of this study. Latif and colleagues ${ }^{1}$ used cumulative incidence of recurrence to address the competing risk of death without recurrence (patients cannot experience recurrence if they die). When Latif and colleagues ${ }^{1}$ performed this analysis, 1 unit of blood transfused was not associated with worse outcomes. Patients with lung cancer are often frail, which can be a challenging adjustment in a multivariable model. Because of their marginal reserve, perhaps transfusions were given more liberally to frail patients, who inherently have a lower survival than more physiologically fit patients. If transfusions are associated with frailty, this could confound the association between blood transfusions and increased mortality. By adequately accounting for competing risks, Latif and colleagues ${ }^{1}$ mitigate the confounding impact of

Latif and colleagues ${ }^{1}$ are to be commended for their rigor and a statistical analysis that enabled a clear picture of patient outcomes. Blaming the immune system may be 
nothing more than chasing the "usual suspects." In reality, immunologic shaming may be a scapegoat for other confounding variables.

\section{References}

1. Latif MJ, Tan KS, Molena D, Huang J, Bott MJ, Park BJ, et al. Perioperative blood transfusion has a dose-dependent relationship with disease recurrence and survival in patients with non-small cell lung cancer. J Thorac Cardiovasc Surg. 2019;157: 2469-77.e10
2. Rueth NM, Parsons HM, Habermann EB, Groth SS, Virnig BA, Tuttle TM, et al The long-term impact of surgical complications after resection of stage I nonsmall cell lung cancer: a population-based survival analysis. Ann Surg. 2011;254: 368-74.

3. Rochling FA, Jones WF, Chau K, DuCharme L, Mimms LT, Moore B, et al. Acute sporadic non-A, non-B, non-C, non-D, non-D, non-E hepatitis. Hepatology. 1997; $25: 478-83$.

4. Whitson BA, Groth SS, Duval SJ, Swanson SJ, Maddaus MA. Surgery for earlystage non-small cell lung cancer: a systematic review of the video-assisted thoracoscopic surgery versus thoracotomy approaches to lobectomy. Ann Thorac Surg. 2008;86:2008-16; discussion 2016-8. 